\title{
发展板块构造: 从洋壳俯冲到大陆碰撞
}

\author{
郑永飞 ${ }^{(1)}$, 叶凯 ${ }^{(2)}$, 张立飞 ${ }^{(3)}$ \\ (1) 中国科学院壳幔物质与环境重点实验室, 中国科学技术大学地球和空间科学学院, 合肥 230026; \\ (2) 岩石圈演化国家重点实验室, 中国科学院地质与地球物理研究所, 北京 100029; \\ (3) 造山带与地壳演化教育部重点实验室, 北京大学地球与空间科学学院, 北京 100871 \\ E-mail: yfzheng@ustc.edu.cn
}

2009-06-17 收稿, 2009-06-18 接受

中国科学院知识创新工程重要方向性项目(编号: KZCX2-YW-131)和国家重点基础研究发展计划(编号: 2009CB825000)资助

摘要 大陆地壳深俯冲与超高压变质的研究不仅带动了中国固体地球科学的发展, 而且为发 展板块构造理论提供了契机. 根据俯冲地壳的性质, 已经认识到俯冲和碰撞分别以两种类型出 现. 就地壳俯冲来说, 存在洋壳俯冲型(例如太平洋周边)和陆壳俯冲型(例如阿尔卑斯造山带). 就大陆碰撞来说, 则存在弧-陆碰撞型(例如喜马拉雅和青藏造山带)和陆-陆碰撞型(例如大别苏鲁造山带). 大陆俯冲带深部化学变化与差异折返、洋壳俯冲与陆壳俯冲之间的时空转换, 将 是今后一个时期大陆动力学研究的重点.

关键词

地壳俯冲

大陆碰撞

超高压变质

大陆动力学
过去 30 年里, 地球科学领域最重要的研究进展 之一就是在世界上二十几条大陆俯冲/碰撞带的变质 表壳岩石中发现并确认柯石英和金刚石 ${ }^{[1,2]}$. 柯石英 和金刚石的发现, 证明它们所赋存的岩石曾经俯冲 到至少 $80 \mathrm{~km}$ 的大陆岩石圈地幔深度而发生了超高 压变质作用 ${ }^{[3]}$. 传统的板块构造理论认为, 大陆地壳 由于密度较低, 因此不可能俯冲到地幔深度. 大陆俯 冲带中超高压变质岩石的发现, 给板块构造理论带 来了革命性的变化 ${ }^{[4,5]}$. 纵观地球上已知的若干超高 压地体, 有几个问题需要考虑: 与其他变质岩相比超 高压岩石有什么特殊之处? 表壳岩石的深俯冲/碰撞 带是否属于普遍现象? 或者仅仅超高压岩石折返的 构造体制具有特别之处?

柯石英和金刚石的发现激动了固体地球科学家, 由此所带来的科学意义对于板块构造理论是深远的. 它将已知的地壳深度变质压力拓展到地幔深度, 数 值上从 $>80 \mathrm{~km}^{[6,7]}$ 扩展到 $>120 \mathrm{~km}^{[8,9]}$, 甚至达到 200 350 km $\frac{[10,11]}{}$. 超高压岩石从地幔深度折返回地 表, 要求特殊的 $P-T$ 条件. 对这些岩石进行同位素年 代学和地球化学研究, 为我们探究深部地质过程打
开了新的视野 [12 14]. 虽然地球科学家对俯冲和折返 过程的解释面临挑战, 但是也正是这些挑战为我们 透视碰撞造山带的地球动力学过程提供了新的切入 点. 这有可能为我们解译上地幔不均一性、幔源岩浆 性质及其多样性提供新的重要依据. 一方面, 这些新 的发现和科学透视植根于矿物学和岩石学研究 ${ }^{[15,16]}$. 另一方面, 超高压变质作用研究的突出进展来自于 对同位素年代学和地球化学数据的动态解释 [13,14].

自从在陆源超高压岩石中发现柯石英和金刚石 以来, 中国科学家从一开始就积极地投入到板块构造 理论的变革之中. 在过去的 20 年里, 他们在洋壳俯冲 到陆壳碰撞这一系列地球动力学过程的研究上做出 了卓越贡献. 2001 2005年在苏鲁造山带东海地区实 施的中国大陆科学钻探(CCSD)工程, 其主孔(MH)深 达5158 km, 连续提取了非常珍贵的超高压岩石样品. 大量的研究结果证明, 大陆和大洋地壳都曾经俯冲到 大陆岩石圈地幔深度, 导致超高压变质岩的形成. 这 不仅为我们发展传统的板块构造理论带来契机, 而且 给固体地球科学研究提出了新的挑战. 国际学术界越 来越意识到, 现阶段研究应充分重视大陆和大洋地壳 
的俯冲和折返过程, 一方面聚焦地壳内部拆离解耦与 差异折返, 另一方面探索板片内部流体活动与化学分 异. 尽管超高压变质岩形成和出露的大地构造背景在 各个造山带存在千差万别, 但是俯冲带深部流体活动 与地壳折返是今后一个时期的研究主题. 通过这类研 究有望回答下列科学问题: (1) 不同成分的超高压变 质岩在地幔深部形成后是如何折返回到地壳浅部的? （2）俯冲带深部高压/超高压矿物脱水和熔融是如何 支配变质流体/熔体形成和演化的? (3) 洋壳与陆壳深 俯冲和折返过程中的流体活动和化学变异有何差异? (4) 俯冲带深部流体活动是如何影响元素和同位素分 异以及交代周围岩片的?

为了进一步探索大陆俯冲带的奥妙, 2009 年国 家科学技术部又启动了一个题为“深俯冲地壳的化学 变化和差异折返”的国家重点基础研究发展计划项目. 这个项目以大陆和大洋俯冲带深部流体活动与地壳 折返为主线, 以深俯冲地壳的化学分异与拆离解耦 为切入点, 通过地质学和地球化学综合研究出露在 我国中部东西向约 $5000 \mathrm{~km}$ 长造山带范围内的典型 大陆型和大洋型超高压变质地体, 恢复深俯冲地壳 的原岩性质及其形成的大地构造背景, 再造典型超 高压变质带的结构和组成, 揭示陆壳与洋壳深俯冲 和折返之间的差异和转换过程, 认识洋壳和陆壳俯 冲带深部流体活动差异及其动力学效应. 通过深入 探讨下列深层次科学问题, 为建立大陆深俯冲和折 返的理论体系提供关键科学依据: (1) 深俯冲陆壳的 多岩板差异折返与启动机制; (2) 深俯冲地壳性质对 流体活动和元素迁移的制约; (3) 深俯冲地壳对邻区 岩石圈及上地幔的影响; (4) 由洋壳俯冲到陆壳碰撞 的时空转换与动力学联系.

本专题以 3 篇文章总结了通过大地构造学、岩石 学、同位素年代学和地球化学方法研究中国境内洋壳 俯冲与陆壳碰撞的最新进展 ${ }^{[17 \sim 19]}$. 结合 2008 年出版 的“超高压变质与大陆深俯冲”专题 3 篇文章 ${ }^{[20 ~ 22] ~}$ 和 近两年零星刊出的 6 篇文章 ${ }^{[23 ~ 28]}$, 可见中国地球科学 家已经在大洋和大陆俯冲带地球动力学研究领域取 得了突出进展. 这 12 篇文章不仅系统评述了中国境 内从大别-苏鲁到西天山乃至青藏造山带出露的超高 压变质地体, 而且充分涵盖了各种用在理解和解释 来自超高压地体岩石的命题和方法. 它一方面对中 国东部大陆俯冲带和西部大洋俯冲带高压/超高压变 质岩的研究进行了全面介绍, 另一方面对深化地壳
深俯冲和大陆碰撞地球动力学研究提出了新的思路. 因此, 这组论文对于任何研究大陆岩石圈地壳和地 幔成因和演化的学者具有参考价值, 特别是对于那 些正在进行大陆俯冲带构造地质学、地球动力学和岩 石学研究的人员来说值得一读.

在板块构造假说提出不久, 就出现了著名的威 尔逊旋回模型, 以下列 4 个阶段来描述大洋盆地的产 生和消亡: (1) 一个大陆的裂陷; (2) 大陆漂移和海底 扩张, 形成大洋盆地; (3) 大洋岩石圈俯冲, 大洋盆 地逐渐关闭; (4) 大陆碰撞, 大洋盆地最终关闭. 板 块构造理论已经得到半个世纪的发展. 目前已经认 识到, 大陆地壳的形成和演化可以概括为下列 6 个阶 段: (1) 洋壳俯冲和岛弧岩浆作用, 引起新生地壳生 长; (2) 弧-弧碰撞, 形成大陆核; (3) 弧-陆碰撞导致 大陆增生, 伴有地壳再造; (4) 陆-(弧)-陆碰撞和大陆 俯冲, 形成超级大陆; (5) 造山带大陆岩石圈裂陷, 引起超级大陆裂解; (6) 大陆漂移和海底扩张, 导致 新一轮俯冲. 在板块汇聚速率或运动方向上的变化 有可能导致大洋与大陆俯冲带之间在地壳再造(变质 作用和岩浆活动)性质和程度上的各种差别. 一方面, 大洋板块俯冲到大洋板块之下产生大洋弧, 引起通 常定义的新生地壳生长. 另一方面, 大洋板块俯冲到 大陆板块之下产生大陆弧, 对应于大陆岩石圈的再 造. 此外, 新生岛弧地壳在增生到大陆边缘之前还不 是大陆地壳的一部分.

随着板块构造的发展, 人们认识到俯冲带变质 作用存在很大差异, 包括地质产状、矿物组合和峰期 变质条件等. 根据俯冲地壳的性质, 可以将俯冲带分 成太平洋型和阿尔卑斯型两种类型 [29]. 太平洋型洋 壳俯冲带以出现与蛇绿岩相关的低温/高压蓝片岩相 和榴辉岩变质岩为主要特征, 而阿尔卑斯型陆壳俯 冲以出现中温/超高压榴辉岩相变质岩为主要特征. 板块在相对较低的地温梯度下俯冲, 将镁铁质和长 英质岩石携带到 30 120 km甚至更大的地幔深度, 分 别产生了太平洋型高压变质带和阿尔卑斯型超高压 变质带. 典型的太平洋型俯冲与数千公里的大洋岩 石圈侧向流动有关, 在玄武质地壳覆盖的大洋板块 之上出现以岛弧火山岩为特征的同俯冲岩浆作用, 形 成新生镁铁质地壳. 相反, 阿尔卑斯型俯冲可能与弧 后盆地闭合、弧-陆和陆-弧-陆碰撞有关, 最终引起大 陆地壳俯冲, 但是在花岗质地壳覆盖的大陆板块之 上盖层之上既没有同俯冲岩浆岩也缺乏新生地壳. 
因此, 阿尔卑斯型碰撞再造先存的地体, 即引起先存 地壳再造而不是新生地壳生长.

虽然这两种类型的板块汇聚作用可以通过大地 构造学观察予以区分, 但是二者之间还有很多过渡 类型. 也是根据俯冲地壳性质，可将大陆碰撞带进一 步分成两种类型. 一种是喜马拉雅山-青藏型, 由阿 尔卑斯型弧-陆碰撞带发展而来(图 1(a)), 伴有同碰撞 变质作用和岩浆活动. 这类碰撞带最终演化为陆-弧陆碰撞造山带(图 1(b)), 发育或不发育高压/超高压变 质作用, 导致了宽阔的陆间造山带和新生地壳的再 造 ${ }^{[30,31]}$. 另一种是大别-苏鲁型, 由花岗质地壳覆盖 的大陆板块俯冲到另外一大陆板块之下形成(图 2(a)), 陆-陆碰撞引起了超高压变质作用, 在碰撞陆块之间 没有新生岛弧出现. 这导致了一个狭窄的陆间造山 带和相对古老地壳的再造 ${ }^{[13]}$. 由于大陆岩石圈地幔 深度条件下长英质陆壳的浮力作用, 一般假设深俯 冲陆壳在大陆-大洋岩石圈过渡带发生板片断离之后 而折返上来(图 2(b)), 往往伴有同折返脱水熔融.

超高压变质地体的折返过程可以划分为两个阶 段: (1) 同碰撞侵出阶段, 漂浮驱动的向上流动或者 构造侵出引起低温/超高压变质岩沿着俯冲通道优先 向上迁移; (2) 碰撞后侵出阶段, 造山带大陆岩石圈 伸展和构造跨塌引起变质核杂岩折返. 就超高压岩 石的折返速率来说, 在这两种类型的碰撞造山带之 间存在显著差别. 快速折返 $(>20 \mathrm{~mm} / \mathrm{a})$ 通常出现在喜 马拉雅山-西藏型碰撞带, 而慢速折返 $(<10 \mathrm{~mm} / \mathrm{a})$ 一 般发生在大别-苏鲁型碰撞带 113$]$. 尽管在这两种类型 的大陆碰撞带都有丰富的碰撞后岩浆岩的产出, 但

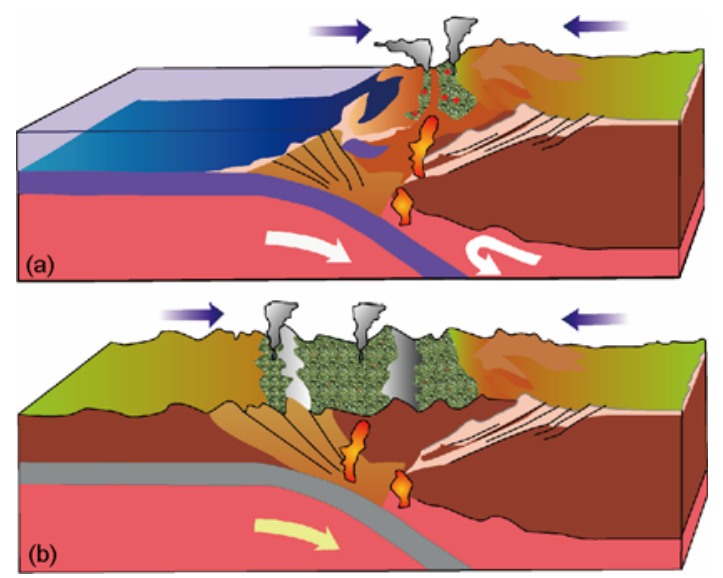

图 1 喜马拉雅山-青藏型大陆碰撞造山带演化示意图 (a) 阿尔卑斯型弧-陆碰撞及其伴随的同时期变质作用和岩浆活动; (b) 陆-弧-陆碰撞及其伴随的高压-超高压变质作用
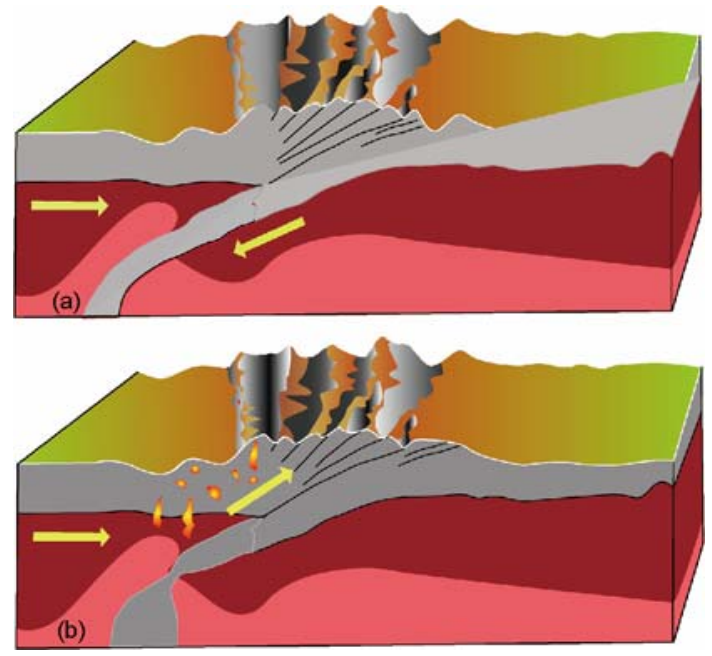

图 2 大别-苏鲁型大陆碰撞造山带示意图

(a) 花岗质地壳覆盖的大陆板块向另一大陆板块俯冲引起陆-陆 碰撞, 二者之间没有新生岛弧; (b) 深俯冲陆壳在大陆大洋岩石圈过渡带发生板片断离而折返

是它们的岩浆源区在放射成因同位素组成上存在很 大差别. 在喜马拉雅山-青藏型造山带新生地壳重熔 非常明显, 而在大别-苏鲁型造山带则相对古老地壳 的深熔作用. 无论如何, 花岗岩是加厚大陆地壳造山 带内部唯一真正丰富的岩浆岩类. 不过, 板块汇聚过 程中大陆地壳净生长的原始地点是太平洋型俯冲带 基础上发育的弧-陆碰撞带, 而不是阿尔卑斯型俯冲 带基础上演化的陆-陆碰撞带.

通过对大别-苏鲁造山带的地表露头岩石和中国 大陆科学钻探岩心样品的研究 112 16,21,32 34], 人们已经 在大陆碰撞和超高压变质的化学地球动力学领域取得 了一系列具有国际影响力的成果. 这些成果在很大程 度上得益于将原位地球化学分析方法与传统岩石学研 究相结合, 成功实施的具有创新性的现代岩石学研究. 这主要涉及各种先进分析技术的综合应用, 特别是将 BSE, SEM和TEM等光学观察与EMP, LA-RAMAN, LA-ICPMS, LA-MC-ICPMS和SIMS等原位分析技术相 结合, 有关分析的空间分辨率可以从几个微米变化到 几百个微米范围. 锆石学方面的研究进展已经成为解

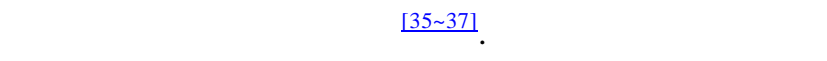
和内部结构与它们的微区微量元素、U-Th-Pb和Lu-Hf 同位素结合起来, 能够在数十微米的显微尺度上区分 不同成因的锆石. 这样许多难以被传统方法解 决的问题在新的技术条件下已经不复存在. 例如, 因 为俯冲带变质过程中不同构造事件的信息分别记录在 
变质生长或重结晶锆石的不同晶域, 所以识别变质锆 石成因是其 $\mathrm{U}-\mathrm{Pb}$ 年龄解释的关键. 由于这个原因, 人 们需要鉴定锆石生长自富水流体、含水熔体还是超临 界流体, 变质重结晶是通过固态转换、交代反应还是 溶解再沉淀机制进行的 ${ }^{[14,38]}$. 因此, 对高压和超高压 变质矿物进行元素和同位素微区分析, 使我们有可能 定量解译地壳岩石俯冲和折返过程中元素迁移与流体 /熔体活动之间的定量关系.

对超高压变质地体的创新性观察和解释是认识 大陆俯冲带构造过程的关键. 基于这一前提, 我们将 大陆地壳俯冲/折返和碰撞造山带构造垮塌等一系列 构造过程引入大陆动力学 [20], 试图将陆内造山作用 纳入板块构造理论格架. 此外, 俯冲带地球化学反映 的物理化学控制是非常明显的 13$]$. 虽然热力学性质 差异使化学反应自发地朝向最小自由能方向发展, 但是动力学因素限制了这样的反应在一个有限的时 间内达到完全平衡. 热力学与动力学之间的竞争决 定了记录在高压/超高压矿物组合中的最终反应状态. 因此, 在俯冲带变质作用进行过程中, 不同成分和不 同位置岩石中变质矿物对 $P-T$ 条件的变化可能具有不 同程度的热力学和动力学响应. 应用这种热力学-动 力学竞争原理, 能够成功地解释超高压变质矿物中 大气降水氧同位素信息在经历地幔旅程之后的保存 (油炸冰淇淋模型 $)^{[12]}$. 就变质地质温压计来说, 由于 折返过程中 $P-T$ 条件的显著变化, 超高压岩石中共存 矿物之间元素和同位素配分的再造是不可避免的. 动力学上, 矿物之间无论是原始平衡的保存还是退 变质再平衡的达到, 都取决于在变化了的 $P-T$ 条件下 是否有流体活动和退变质作用的持续时间. 榴辉岩 相矿物(例如, 绿辉石和多硅白云母)能否在角闪岩相 叠加变质的岩石中得以亚稳态保存, 同样取决于是 否存在角闪岩相退变质流体 ${ }^{[14]}$ 和不同 $P-T$ 条件下角闪 岩相退变质反应的持续时间 ${ }^{[13]}$. 相同的原理同样可 以应用到超高压岩石折返过程中脱水熔融是否能够 在超高压-高压体制下出现 ${ }^{[19,39,40]}$.

以超高压变质岩及其相关的岩石作为天然实验 室, 地球科学家能够了解大陆俯冲带变质作用及其
内在的地球动力学. 有 12 个方面的基本问题需要考 虑 ${ }^{[20]}$ : (1) 超高压变质岩的空间分布, (2) 超高压变质 作用的发生时间，(3) 超高压变质作用的持续时间, （4）深俯冲地壳的原岩性质，(5) 大陆碰撞过程中的 俯冲侵蚀和地壳拆离, (6) 大陆俯冲的可能深度, （7）大陆深俯冲带流体活动性，(8) 大陆碰撞过程中 的部分熔融, (9) 大陆深俯冲带元素活动性, (10) 俯 冲大陆地壳物质的再循环，(11）碰撞后岩浆作用的 地球动力学机制, (12) 碰撞造山带岩石圈结构. 虽然 在弧-陆和陆-陆碰撞造山带都有洋壳和陆壳的深俯 冲, 但是由于密度差别, 镁铁质超高压变质岩最有可 能是被长英质超高压变质岩包裹而得以折返. 因此, 超高压地体中长英质岩石占主导地位, 零星出现的 镁铁质岩石主要以透镜体、布丁状产出, 极少以公里 尺度的块体出现. 由于长英质超高压变质岩中矿物 的水含量很高, 它们在折返过程中易于受到退变质 作用的改造, 结果很少保留有超高压变质的矿物学 记录. 相反, 镁铁质超高压岩石在退变质反应中相对 稳定. 因此, 在超高压变质岩研究中地球科学家们更 多关注的是镁铁质榴辉岩而不是长英质片麻岩.

尽管上述 12 个方面是从大别-苏鲁造山带的实例 研究概括而来, 但是这个实例具有许多普遍意义上 的优点. 它通过一个清楚的地质背景获得地球动力 学透视, 使我们能够评价大陆碰撞带在侧向和垂向 两个方面的变化. 不同等级变质单元存在不同的 $P-T-t$ 轨迹, 允许我们再造大陆碰撞期间俯冲和折返 的全过程. 它同样可以用作一个参照系与世界上其 他背景的大陆碰撞带进行比较. 事实上, 对大别-苏 鲁造山带超高压岩石中各种记录的研究, 已经极大 地改进了我们对大陆地壳俯冲/折返地球动力学过程 的理解. 某些最有前景的研究方向在于对一些超高 压地体进行高度集成的野外观察、实验分析和理论模 拟. 无论对于哪个大陆碰撞带, 一旦上述 12 个方面 的基本问题在区域尺度和普遍意义上得以解决, 结 果必然会深化我们对大洋俯冲到大陆碰撞这一系列 地球动力学过程的理解. 这也为我们全面认识大陆 俯冲带过程的地球动力学提供了参照系.

\section{参考文献}

\footnotetext{
Chopin C. Ultrahigh-pressure metamorphism: Tracing continental crust into the mantle. Earth Planet Sci Lett, 2003, 212: 1-14[doi] Ernst W G, Liou J G. High- and ultrahigh-pressure metamorphism: Past results and future prospects. Am Mineral, 2008, 93: 1771-1786[doi] 郑永飞. 大陆深俯冲的矿物学证据. 科学通报, 2003, 48: 991一992
} 
$9 \quad \mathrm{Xu} \mathrm{S}$ T, Okay A I, Ji S Y, et al. Didoi] 1992, 256: 80-82[doi]

10 Ye K, Cong B L, Ye D N. The possible subduction of continental material to depths greater than $200 \mathrm{~km}$. Nature, 2000, 407: 734-736

11 Liu L, Zhang J F, Green II H W, et al. Evidence of former stishovite in metamorphosed sediments, implying subduction to > 350 km. Earth Planet Sci Lett, 2007, 263: 180-191

12 Zheng Y F, Fu B, Gong B, et al. Stable isotope geochemistry of ultrahigh pressure metamorphic rocks from the Dabie-Sulu Orogen in China: Implications for geodynamics and fluid regime. Earth Sci Rev, 2003, 62: 105-161 [doi]

13 Zheng Y F, Chen R X, Zhao Z F. Chemical geodynamics of continental subduction-zone metamorphism: Insights from studies of the Chinese Continental Scientific Drilling (CCSD) core samples. Tectonophysics, 2009, [doi]

14 Zheng Y F. Fluid regime in continental subduction zones: Petrological insights from ultrahigh-pressure metamorphic rocks. J Geol Soc, 2009, 166: 763-782[doi]

15 Liou J G, Ernst W G, Zhang R Y, et al. Ultrahigh-pressure minerals and metamorphic terranes-The view from China. J Asian Earth Sci, 2009, 35: 199-231[doi]

16 Zhang R Y, Liou J G, Ernst W G. The Dabie-Sulu continental collision zone: A comprehensive review. Gondwana Res, 2009, 16: 126[doi]

17 张开均, 唐显春. 青藏高原腹地榴辉岩研究进展及其地球动力学意义. 科学通报, 2009, 54: 1804一1814

18 吴元保. 大陆造山过程的多期演化: 以西大别为例. 科学通报, 2009, 54: 1815-1825

19 曾令森, 梁凤华, Asimow P, 等. 深俯冲陆壳岩石部分熔融与苏鲁超高压榴辉岩中长英质多晶包裹体的形成. 科学通报, 2009, 54: $1826-1840$

20 郑永飞. 超高压变质与大陆碰撞研究进展: 以大别-苏鲁造山带为例. 科学通报, 2007, 53: 2129一 2152

21 刘贻灿, 李曙光. 俯冲陆壳内部的拆离和超高压岩石的多板片差异折返: 以大别-苏鲁造山带为例. 科学通报, 2007, 53: $2153-2174$

22 张立飞, 吕增, 张贵宾, 等. 大洋型超高压变质带的地质特征及其研究意义一一以西南天山、柴北缘超高压变质带为例. 科 学通报, 2007, 52: 2169-2174

Zheng Y F, Wu R X, Wu Y B, et al. Rift melting of juvenile arc-derived crust and granitic rocks in the Jiangnan Orogen, South China. Precambrian Res, 2008, 163: 351-383[doi]

32 Zhang Z M, Shen K, Sun W D, et al. Fluids in deeply subducted continental crust: Petrology, mineral chemistry and fluid inclusion of UHP metamorphic veins from the Sulu orogen, eastern China. Geochim Cosmochim Acta, 2008, 72: 3200-3228[doi]

Xu Z Q, Yang W C, Ji S C, et al. Deep root of a continent-continent collision belt: Evidence from the Chinese Continental Scientific Drilling (CCSD) deep borehole in the Sulu ultrahigh-pressure (HP-UHP) metamorphic terrane, China. Tectonophysics, 2009,[doi] Implications for mantle wedge convection during progressive oceanic and continental subduction. Lithos, 2009, 109: 155-175[doi]

35 Wu Y B, Zheng Y F, Zhao Z F, et al. U-Pb, Hf and O isotope evidence for two episodes of fluid-assisted zircon growth in marble-hosted eclogites from the Dabie orogen. Geochim Cosmochim Acta, 2006, 70: 3743-3761 [doi]

36 Liu D Y, Jian P, Kröner A, et al. Dating of prograde metamorphic events deciphered from episodic zircon growth in rocks of the Dabie-Sulu UHP complex, China. Earth Planet Sci Lett, 2006, 250: 650-666[doi]

37 Liu F L, Gerdes A, Zeng L S, et al. SHRIMP U-Pb dating, trace element and Lu-Hf isotope system of coesite-bearing zircon from amphibolite in SW Sulu UHP terrane, eastern China. Geochim Cosmochim Acta, 2008, 72: 2973-3000[doi]

38 Xia Q X, Zheng Y F, Yuan H L, et al. Lu-Hf and U-Th-Pb isotope distinction between metamorphic growth and recrystallization of zircon from eclogite-facies metagranite in the Dabie orogen. Lithos, 2009, [doi]

39 Xia Q X, Zheng Y F, Zhou L G. Dehydration and melting during continental collision: Constraints from element and isotope geochemistry of low-T/UHP granitic gneiss in the Dabie orogen. Chem Geol, 2008, 247: 36-65[doi]

40 Zhao Z F, Zheng Y F, Chen R X, et al. Element mobility in mafic and felsic ultrahigh-pressure metamorphic rocks during continental collision. Geochim Cosmochim Acta, 2007, 71: 5244-5266[doi] 